\title{
Do patients with low volume prostate cancer have prostate specific antigen recurrence following radical prostatectomy?
}

\author{
B Furusato, ${ }^{1,3}$ I L Rosner, ${ }^{2}$ D Osborn, ${ }^{2}$ A Ali, ${ }^{3}$ S Srivastava, ${ }^{3}$ C J Davis, ${ }^{1}$ I A Sesterhenn, ${ }^{1}$ \\ D G McLeod ${ }^{2,3}$
}

${ }^{1}$ Department of Genitourinary Pathology, Armed Forces Institute of Pathology, Washington, DC, USA;

${ }^{2}$ Department of Surgery, Urology Service, Walter Reed Army Medical Center Washington, DC, USA; ${ }^{3}$ Center for Prostate Disease Research, Department of Surgery, Uniformed Services University of the Health Sciences, Bethesda Maryland, USA

\section{Correspondence to:}

David G McLeod, Center for Prostate Disease Research and Director, Urologic Oncology, 6900 Georgia Ave, NW Washington, DC 20307, USA; dgmcleod@verizon.net

$\mathrm{BF}$, ILR and DO contributed equally to this work.

CJD is deceased.

Accepted 15 May 2008 Published Online First 13 June 2008

\section{ABSTRACT}

Aims: The objective of this study was to determine the incidence of prostate specific antigen (PSA) relapse in patients with low volume prostate cancer following radical prostatectomy.

Methods: Between 1993 and 2001, 50 of 717 patients had total tumour volumes of less than $0.5 \mathrm{~cm}^{3}$ following radical prostatectomy. Biochemical recurrence was defined as two consecutive values of serum PSA levels of $0.2 \mathrm{ng} / \mathrm{ml}$ or greater

Results: Median follow-up of the 50 patients was 58 months. In five of the 50 patients (10\%), PSA recurrence was observed. All of these five cases had Gleason score of $3+3$ (well and/or moderately differentiated), organ confined and surgical margin negative tumours. In three of the five cases, capsular incision resulted in benign glands extending into the surgical margin.

Conclusions: Five of 50 cases had PSA failure. In three of the five patients, benign glands located in the margin could explain the "PSA recurrence". However, in the other two patients, none of the pathological parameters correlated with measurable PSA levels. The explanation for their PSA failure is unclear.

Serum prostate specific antigen (PSA) after radical prostatectomy (RP) is considered a surrogate marker of treatment failure. ${ }^{1}$ The definition of an "indolent" or "clinically insignificant" prostatic carcinoma in RP specimens varies. ${ }^{1-10}$

Epstein et al. ${ }^{9}$ examined a consecutive series of 157 men who underwent radical prostatectomy for clinical stage T1c disease compared with 64 clinical stage T1a and 439 clinical stage T2 cancers, and proposed a cut-off volume for clinically insignificant prostate carcinoma of less than $0.2 \mathrm{~cm}^{3}$, because $13 \%$ (three of 23 ) cases with tumour volume between 0.2 and $0.5 \mathrm{~cm}^{3}$ were not always organ confined in clinical stage T2 tumours. Currently, a tumour volume of less than $0.5 \mathrm{~cm}^{3}$ without any poorly differentiated element (Gleason pattern 4 or 5) and confined to the prostate is the most widely accepted definition for clinically insignificant or indolent prostate carcinoma. ${ }^{11} 12$

The objective of this study was to determine the incidence of serological (PSA) failure defined as two consecutive postoperative serum PSA levels of $0.2 \mathrm{ng} / \mathrm{ml}$ or greater in patients with organ confined and surgical margin negative tumours. These tumours were less than $0.5 \mathrm{~cm}^{3}$, including the presence of poorly differentiated tumour elements in two patients (Gleason pattern 4) following RP.

\section{METHODS}

With institutional review broad approval from the institution, data from 717 patients treated with radical prostatectomy from 1993 to 2001 at the Urology Service at Walter Reed Army Medical Center were obtained. The collected information included patient age at the time of surgery, race, clinical stage, biopsy grade, preoperative PSA, prostatectomy data (specimen weight, tumour volume, grade, stage and surgical margin status) and follow-up PSA data.

The prostatectomy specimens were sectioned and totally embedded as whole mounts at the Armed Forces Institute of Pathology. ${ }^{13}$ Each prostate was sectioned at $0.22 \mathrm{~cm}$ intervals in a transverse plane perpendicular to the long axis of the posterior surface of the prostate, and completely embedded as a whole mount. The volume of each tumour was calculated in three dimensions (apex to base, right to left, and anterior to posterior) using the largest dimension in each direction. The tumour volume did not include the shrinkage factor (1.25) to correct for fixation and embedding. ${ }^{14}$ The total tumour volume was the sum of the tumour volumes of all measurable foci. The presence of benign glands in the inked surgical margins was also recorded.

\section{RESULTS}

Fifty of the 717 patients had total tumour volumes less than $0.5 \mathrm{~cm}^{3}$. Their demographics are presented in table 1.

The median PSA follow up was 58 months (range 12-117 months). If the eight patients with less than 36 months follow-up who did not return for continuous observation are excluded, then the median follow-up time would be 61 months (range 36-117 months).

The mean age at the time of surgery was 61 years (range $41-74$ years). The mean preoperative PSA was $4.9 \mathrm{ng} / \mathrm{ml}$ (range $0.4-19.7 \mathrm{ng} / \mathrm{ml}$ ) and the mean prostate weight was $51.9 \mathrm{~g}$ (range 17120 g). Forty-two patients had multifocal tumours. The mean total number of tumours was four (range 1-12), and the mean total tumour volume was $0.20 \mathrm{~cm}^{3}$ (range $0.02-0.45 \mathrm{~cm}^{3}$ ). All tumours were organ confined and surgical margins were negative. Nineteen of the 50 cases had benign glands located into the surgical margin. The
This paper is freely availat online under the BMJ Journa unlocked scheme, see http $/ /$ jcp.bmj.com/info/unlocked.dt 
Table 1 Characteristics of men with organ confined, surgical margin negative and small volume tumour less than $0.5 \mathrm{~cm}^{3}$

\begin{tabular}{|c|c|}
\hline Characteristic & $\begin{array}{l}\text { No. of patients }(\%) \\
\mathbf{n}=\mathbf{5 0}\end{array}$ \\
\hline \multicolumn{2}{|l|}{ Age (years) } \\
\hline$<61$ & $18(36)$ \\
\hline $61-65$ & $15(30)$ \\
\hline$>65$ & $17(34)$ \\
\hline \multicolumn{2}{|l|}{ Race } \\
\hline African-American & $8(16)$ \\
\hline Caucasian & $42(84)$ \\
\hline \multicolumn{2}{|c|}{ Preoperative PSA level (ng/ml) } \\
\hline$<4$ & $21(42)$ \\
\hline $4-10$ & $26(52)$ \\
\hline$>10$ & $3(6)$ \\
\hline \multicolumn{2}{|l|}{ Pathological stage* } \\
\hline $\mathrm{pT2a}$ & $10(20)$ \\
\hline $\mathrm{pT} 2 \mathrm{~b}$ & $5(10)$ \\
\hline pT2c & $35(70)$ \\
\hline \multicolumn{2}{|c|}{ Total tumour volume $\left(\mathrm{cm}^{3}\right)$} \\
\hline$<0.3$ & $33(66)$ \\
\hline 0.3 to $<0.5$ & $17(34)$ \\
\hline \multicolumn{2}{|l|}{ Gleason score } \\
\hline 4 & $1(2)$ \\
\hline 5 & $9(18)$ \\
\hline 6 & $38(76)$ \\
\hline $3+4$ & $2(4)$ \\
\hline $4+3$ & $0(0)$ \\
\hline \multicolumn{2}{|c|}{ WHO tumour differentiation } \\
\hline Well & $36(72)$ \\
\hline Moderate & $12(24)$ \\
\hline Poor & $2(4)$ \\
\hline \multicolumn{2}{|c|}{ Benign glands in the surgical margin } \\
\hline Positive & $19(38)$ \\
\hline Negative & $31(62)$ \\
\hline \multicolumn{2}{|c|}{ Multifocality (number of tumours) } \\
\hline Single & $8(16)$ \\
\hline Multifocal & $42(84)$ \\
\hline
\end{tabular}

*1992 tumour, node, metastases (TNM) staging system.

PSA, prostate specific antigen; WHO, World Health Organization.

distribution of Gleason scores was as follows: Gleason score less than 6 (10 cases), Gleason score 6 (38 cases), Gleason score $3+4$ (two cases).

In five of the 50 cases, postoperative serum PSA levels with two consecutive values of $0.2 \mathrm{ng} / \mathrm{ml}$ up to $5.4 \mathrm{ng} / \mathrm{ml}$ were observed. In general, postoperative PSA levels had an undulating pattern. A scheme of the postoperative PSA level of the five cases is presented in fig 1. All five cases had Gleason scores of 6 (well and/or moderately differentiated tumours). In three of the five cases, benign glands extended into the surgical margin (table 2).

Case 1 with benign gland extending into the surgical margin and a postoperative rapidly rising PSA up to $5.4 \mathrm{ng} / \mathrm{ml}$ received hormonal treatment.

\section{DISCUSSION}

The pathological findings are similar to those described by Cheng et al. with respect to mean age, prostate size, tumour volume and tumour grade. ${ }^{15}$

In this study, we included PSA follow-up data. We found that men with clinically insignificant tumour are at risk for PSA relapse; these findings are similar to those of Sengupta et al. ${ }^{16}$
Table 2 Demographic data on patients with postoperative prostate specific antigen (PSA) relapse

\begin{tabular}{lccccc}
\hline & \multicolumn{7}{l}{ Case no. } \\
\cline { 2 - 6 } Characteristic & $\mathbf{1}$ & $\mathbf{2}$ & $\mathbf{3}$ & $\mathbf{4}$ & $\mathbf{5}$ \\
\hline Age (years) & 66 & 67 & 64 & 53 & 41 \\
Prostate weight $(\mathrm{g})$ & 120 & 106 & 78 & 32 & 30 \\
Preoperative PSA (ng/ml) & 19.7 & 16.9 & 12.3 & 1.2 & 0.8 \\
Clinical T stage & $\mathrm{T} 1 \mathrm{c}$ & $\mathrm{T} 1 \mathrm{c}$ & $\mathrm{T} 1 \mathrm{c}$ & $\mathrm{T} 1 \mathrm{c}$ & $\mathrm{T} 2 \mathrm{a}$ \\
Pathology T Stage & $\mathrm{T} 2 \mathrm{a}$ & $\mathrm{T} 2 \mathrm{c}$ & $\mathrm{T} 2 \mathrm{c}$ & $\mathrm{T} 2 \mathrm{c}$ & $\mathrm{T} 2 \mathrm{c}$ \\
Index tumour volume $\left(\mathrm{cm}^{3}\right)$ & 0.2 & 0.1 & 0.2 & 0.3 & 0.3 \\
Total tumour volume $\left(\mathrm{cm}^{3}\right.$ ) & 0.2 & 0.2 & 0.4 & 0.3 & 0.4 \\
Prostate volume $\left(\mathrm{cm}^{3}\right.$ ) & 175.7 & 230 & 130 & 33.7 & 40 \\
Surgical margin status & Neg & Neg & Neg & Neg & Neg \\
Benign glands extend to & Yes & No & Yes & No & Yes \\
margin status & & & & & \\
Total number of tumour foci & 2 & 10 & 7 & 7 & 4 \\
Gleason score & 5 & 6 & 6 & 5 & 6 \\
Tumour differentiation & Well & Well & Mod & Well & Mod \\
\hline
\end{tabular}

All patients were Caucasian.

Mod, moderate; Neg, negative.

The two patients with Gleason pattern 4 did not have biochemical recurrence at this time (less than 60 months follow-up). The debate of the prognostic significance of small amounts of poorly differentiated carcinoma is still ongoing. Long-term follow-up of the two patients with high-grade tumour is essential.

Albertsen et al. confirmed the long-term impact on mortality of localised prostate cancer in a large population based study. ${ }^{17}$ The probability of death from prostate cancer within 15 years of diagnosis depended on the histological grade and patient age at diagnosis. Patients with a well-differentiated tumour had a low $(4-7 \%)$ probability of death from cancer within 15 years. In our patient population, biochemical recurrence was found in five of 50 patients. In three of the five patients the "serological failure" was probably due to residual benign prostatic tissue. In our experience, benign prostate tissue in the surgical margin of pT2 margin negative tumours can be the source of biochemical PSA recurrence in between $7 \%$ and $10 \%$ of these cases, in contrast to less than $5 \%$ in $\mathrm{pT} 2$ surgical margin negative cases. These patients have an undulating pattern of measurable PSA. In such patients, biopsies of the prostate bed can have benign prostatic tissue. However, it is not possible to exclude preoperative spread via circulating tumour cells. The other two patients may represent the rare example of a low grade (well-differentiated tumour or Gleason score 6) and low volume but biologically aggressive tumour. It is possible that these two patients may have ectopic prostatic tissue in the urethra or bladder. The other explanation may be extension of cancer cells to the periprostatic tissue via lymphatics, even though the cases with recurrence were checked by immunohistochemistry (D240) for lymphatic invasion, and none was detected.

Evaluation of circulating tumour cells in these patient blood samples is ongoing. This finding has to be further evaluated in the large cohort study to determine the significance.

All but one (case 1) of the five patients with PSA relapse have been followed without any hormonal treatment. To date, none of the five patients has detectable metastases, which could be due to the lack of long-term follow-up greater than 15 years, as in the Albertsen et al. study. ${ }^{17}$

This study underscores the fact that PSA might be a poor surrogate to determine actual progression in this type of situation. It remains to be seen if classical clinicopathological 
Figure 1 Postoperative prostate specific antigen (PSA) level of the five patients with PSA relapse.

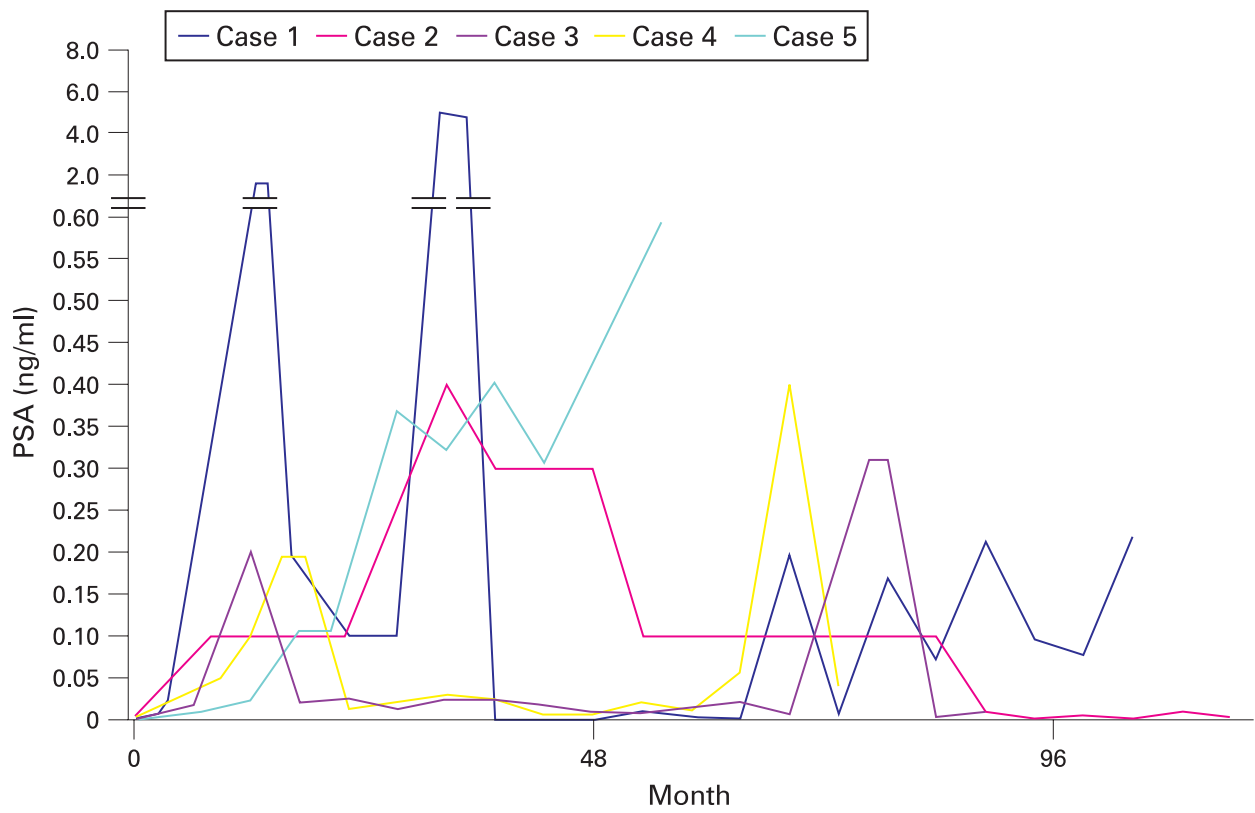

3. Goto $\mathbf{Y}$, Ohori M, Arakawa A, et al. Distinguishing clinically important from unimportant prostate cancers before treatment: value of systematic biopsies. J Urol 1996;156:1059-63.

4. Irwin MB, Trapasso JG. Identification of insignificant prostate cancers: analysis of preoperative parameters. Urology 1994:44:862-7.

5. Chan TY, Chan DY, Stutzman KL, et al. Does increased needle biopsy sampling of the prostate detect a higher number of potentially insignificant tumors? J Urol 2001:166:2181-4.

6. Noguchi M, Stamey TA, McNeal JE, et al. Relationship between systematic biopsies and histological features of 222 radical prostatectomy specimens: lack of prediction of tumor significance for men with nonpalpable prostate cancer. J Urol 2001;166:104-9

7. Elgamal AA, Van Poppel HP, Van de Voorde WM, et al. Impalpable invisible stage T1c prostate cancer: characteristics and clinical relevance in 100 radical prostatectomy specimens-a different view. J Urol 1997;157:244-50.

characterisation or molecular studies combined with postoperative serum PSA level can adequately define small tumours as clinically indolent or insignificant.

Acknowledgements: The authors thank Ms Denise Young for preparation of the prostate samples and Ms Stephanie Shaar for manuscript preparation.

Funding: This research was supported by the Center for Prostate Disease Research Program through the Henry M Jackson Foundation for the Advancement of Military Medicine under contract number HU001-04-C-1502 and by NIH Grant R01 DK065977 (DM and SS).

Competing interests: The views expressed in this article are those of the authors and do not reflect the official policy of the Department of the Army, Department of Defense, or the U.S. Government. The authors have indicated no potential conflicts of interest.

Ethics approval: Ethics approval was obtained from the ethics committee of the Walter Reed Army Medical Centre.

\section{REFERENCES}

1. Stamey TA, Freiha FS, McNeal JE, et al. Localized prostate cancer. Relationship of tumor volume to clinical significance for treatment of prostate cancer. Cancer 1993;71:933-8.

2. Epstein JI, Chan DW, Sokoll LJ, et al. Nonpalpable stage T1c prostate cancer: prediction of insignificant disease using free/total prostate specific antigen levels and needle biopsy findings. J Urol 1998;160:2407-11. 